\title{
Electrochemical Detection of Tripelennamine Hydrochloride Voltammetrically at Glassy Carbon Electrode
}

\author{
Jayant Ira Gowda ${ }^{1,}$, , Rohini Manohar Hanabaratti ${ }^{2}$, Sharanappa Thotappa Nandibewoor ${ }^{3}$ \\ ${ }^{1}$ Post Graduate Department of Studies in Chemistry, Parappa Channappa Jabin Science College, Hubballi, Karnataka, India \\ ${ }^{2}$ Department of Chemistry, Karnatak Science College, Dharwad, Karnataka, India \\ ${ }^{3}$ Post Graduate Department of Studies in Chemistry, Karnatak University, Dharwad, Karnataka, India
}

Email address:

jayantgowda4@gmail.com (J. I. Gowda)

${ }^{*}$ Corresponding author

\section{To cite this article:}

Jayant Ira Gowda, Rohini Manohar Hanabaratti, Sharanappa Thotappa Nandibewoor. Electrochemical Detection of Tripelennamine Hydrochloride Voltammetrically at Glassy Carbon Electrode. Science Journal of Analytical Chemistry. Vol. 7, No. 5, 2019 , pp. $92-97$. doi: $10.11648 /$ j.sjac.20190705.11

Received: July 1, 2019; Accepted: August 12, 2019; Published: November 25, 2019

\begin{abstract}
Tripelennamine hydrochloride (TPA) primarily acts as first generation antihistamine psychoactive or H1 receptor antagonist and an antipruritic drug. In the present study, the voltammetric behavior of TPA was studied using glassy carbon electrode with $\mathrm{pH}$ ranging from 4.2 to 10.4. Cyclic voltammetry (CV) and Differential pulse voltammetric (DPV) techniques have beenemployed in order to elucidate an irreversible electrodic reaction with maximum anodic peak current at $\mathrm{pH}$ 7.0. Surface area of the electrode was calculated and was found to be $0.0202 \mathrm{~cm}^{2}$. Scan rate variation shows that electrodic reaction involves electron transfer with diffusion controlled mass transfer process. The heterogeneous electron transfer rate constant $\left(\mathrm{k}^{0}\right)$ was obtained to be $1.332 \times 10^{3} \mathrm{~s}^{-1}$. A linear relationship between peak current and TPA concentrations was obtained from $0.9 \times 10^{-7} \mathrm{M}$ to $10.0 \times 10^{-5} \mathrm{M}$ by using DPV and limit of detection of $9.7 \times 10^{-8} \mathrm{M}$ was estimated. In addition, a sensitive voltammetric method was developed, and it was successfully applied for TPA determination in pharmaceutical sample and human urine samples.The present method was also applied for the determination of TPA in pharmaceutical samples, with satisfactory recoveries from $95.32 \%$ to $100.12 \%$.
\end{abstract}

Keywords: Tripelennamine Hydrochloride, Glassy Carbon Electrode, Detection Limit, Calibration Plot

\section{Introduction}

In the last few decades electrochemical methods are most widely studied and accepted for the determination of electroactive compounds in pharmaceutical samples and physiological fluids due to its simple, sensitive, rapid and economical properties $[1,2]$. Particularly development of voltammetric methods for both analysis and determination of medicinally important drugs such as anticancer, antihistemine, anti HIV, antihistamine etc. has been received much more importance for the scientific growth of electroanalytical research [3-13]. Electroanalytical chemistry along with the use of oxidation-reduction reactions and other charge-transfer phenomena had its origins eight decades ago. It is one of the fundamental sub disciplines of analytical chemistry.
Tripelennamine hydrochloride (TPA, Chemical structure as given in Figure 1) is a member of pyridine and ethylenediamine classes. It is first generation antihistamine psychoactive drug as an antipruritic. It is used in the treatment of laminitis, allergy, asthma, hay fever, rhinitus and urticaria. Tripelennamine acts primarily as an antihistamine, or $\mathrm{H}_{1}$ receptor antagonist. In addition to its antihistamine properties, tripelennamine also acts as a weak serotonin reuptake inhibitor (SRI) and dopamine reuptake inhibitor (DRI) [14-17]. Because of its serotonin reuptake inhibitor (SRI) properties, tripelennamine was used as basis for the development of selective serotonin reuptake inhibitor (SSRI) fluvoxamine (Luvox) [18]. In Addition, due to its DRI properties, it is occasionally abused as recreational drug. 


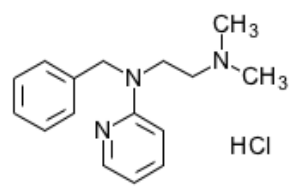

Figure 1. Chemical structure Tripelennamine hydrochloride.

In view of pharmaceutical importance and biological significance of the drug and to develop a simple, low-cost direct current voltammetric method for the determination of TPA, present work had been carried out. We optimized all experimental parameters and developed an electro analytical method for its determination. The proposed method was also applied to the determination of TPA in urine samples.

\section{Experimental}

\subsection{Reagents and Chemicals}

Tripelennamine hydrochloride (TPA) was purchased from Sigma Aldrich (Mumbai, India). TPA containing tablet Azaron was purchased from Omega Pharmaceutical and Health Care Products (India). All other solvents and materials used were of analytical grade.

\subsection{Instrumentation and Analytical Procedure}

The electrochemical experiments were performed with CHI630D Electrochemical analyzer (Austria, USA) with the three electrode system. Glassy carbon electrode was used as working electrode, a platinum wire as auxiliary electrode, and an $\mathrm{Ag} / \mathrm{AgCl}(3.0 \mathrm{M} \mathrm{KCl})$ as reference electrode, respectively. $\mathrm{pH}$ measurements were performed with Elico LI120 pH meter (Elico Ltd., India). Experiments were carried out at room temperature.

The parameters for differential pulse voltammetry (DPV) were Initial potential: $0.4 \mathrm{~V}$; Final potential: $0.9 \mathrm{~V}$; Increase potential: 0.004V; Amplitude: 0.05V; Frequency: $15 \mathrm{~Hz}$; Quit time: $2 \mathrm{~s}$; Sensitivity: $1 \times 10^{-6} \mathrm{~A} \backslash \mathrm{V}$.

\subsection{Measurement Procedure}

Stock solution of 1.0 mM TPA was prepared by dissolving the desired amount in double distilled water. Required amount of stock solution was added to electrolytic cell containing phosphate buffer solution. Voltammograms were then recorded using voltammetric analyzer under optimized parameters.

\subsection{Area of the Electrode}

The area of electrode was obtained by cyclic voltammetric method using $0.1 \mathrm{mMK}_{3} \mathrm{Fe}(\mathrm{CN})_{6}$ as a probe at different scan rates as shown in Figure 2. For a reversible process, the following Randles-Sevcik equation (1) [19] can be used to calculate area of the electrode:

$$
i_{p a}=\left(2.69 \times 10^{-5}\right) \mathrm{n}^{\frac{3}{2}} \mathrm{AD}_{0}^{\frac{1}{2}} \mathrm{C}_{0} v^{\frac{1}{2}}
$$

where $i_{p a}$ refers to the anodic peak current, $n$ is the number of electrons transferred, $A$ is surface area of the electrode, $D_{O}$ is diffusion coefficient, $\mathrm{m}$ is scan rate and $\mathrm{C}_{O}$ is concentration of $\mathrm{K}_{3} \mathrm{Fe}(\mathrm{CN})_{6}$. For $0.1 \mathrm{mM} \mathrm{K}_{3} \mathrm{Fe}(\mathrm{CN})_{6}$ in $0.1 \mathrm{M} \mathrm{KCl}$ electrolyte, $\mathrm{n}=1, \mathrm{D}_{\mathrm{O}}=7.6 \times 10^{-6} \mathrm{~cm}^{2} \mathrm{~s}^{-1}[19]$, then from the slope of the plot of $\mathrm{i}_{\mathrm{pa}}$ versus $v^{1 / 2}$, surface area of the electrode can be calculated. In our experiment slope was $14.96 \times 10^{-6}$ $\mu \mathrm{A}\left(\mathrm{Vs}^{-1}\right)^{-1 / 2}$ and area of the electrode was calculated to be $0.0202 \mathrm{~cm}^{2}$.

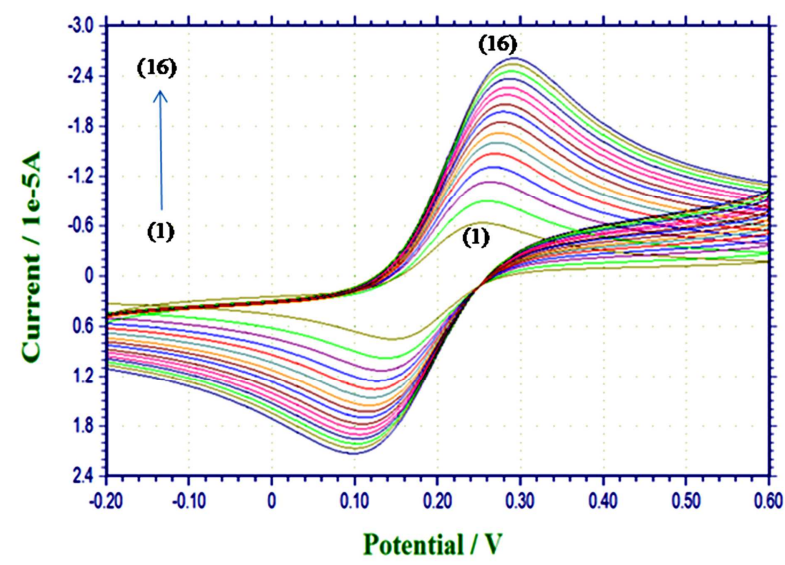

Figure 2. Cyclic voltammogram of $0.1 \mathrm{mM} \mathrm{K}_{3} \mathrm{Fe}(\mathrm{CN})_{6}$ in $0.1 \mathrm{M} \mathrm{KCl}$ solution at different scan rates (1) - (16): $25 \mathrm{mV} / \mathrm{s}-400 \mathrm{mV} / \mathrm{s}$.

\subsection{Standard and Pharmaceutical Sample Preparation}

The electrochemical techniques, especially voltammetry, had gained steadily importance during recent years. Such electrochemical techniques have been applied for the determination of pharmaceutical compounds in dosage forms (tablets, capsules, injections and suspension) and biological samples (real and spiked urine samples, blood and serum).

The commercially available tablets of TPA were weighed and powdered using pastel mortars. A portion of the powder equivalent to about $1.0 \mathrm{mM}$ was weighed accurately, transferred to a $100 \mathrm{~mL}$ calibrated flask and completed the volume with double distilled water. It was then sonicated for 15 min to effect complete dissolution, and diluted to volume with water. Suitable amounts of this solution were taken and analyzed. The amount of TPA in tablet was calculated using a calibration graph or regression equation.

Recovery experiments were carried out by the standard addition method. Recovery study helps us to know the accuracy of proposed method, and to check interference from excipients used in the dosage forms. This study was performed by addition of known amounts of TPA to known concentration of the tablets. The resulting mixture was analyzed as in pure TPA.

\subsection{Determination of TPA in Spiked Human Urine and Plasma Samples}

Using the calibration curve method, application of GCE for the determination of TPA in human urine was also investigated. 
The urine sample was diluted 100 times with $0.2 \mathrm{M}$ PBS (pH $=7.0$ ) to fit the calibration curve and to reduce matrix effect. No other pre-treatment process was performed.

\section{Results and Discussion}

\subsection{Electrochemical Response of TPA at Glassy Carbon Electrode}

Figure 3 shows the cyclic voltammograms of TPA at glassy carbon electrode. It can be seen that TPA exhibits an anodic peak at $0.78 \mathrm{~V}$ in $\mathrm{pH} 7.0$ phosphate buffer solution with scan rate $50 \mathrm{mVs}^{-1}$. On scanning in the negative direction, no reduction peak was observed in this potential range, showing that oxidation of TPA is an irreversible process.

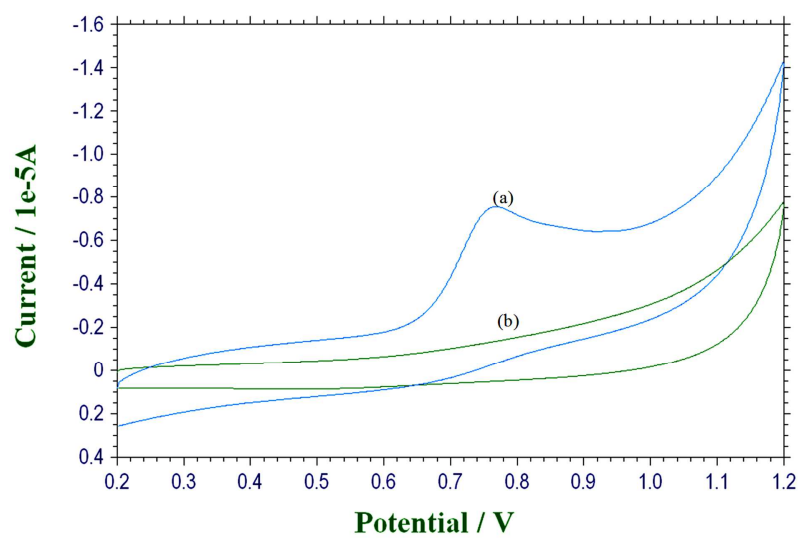

Figure 3. Cyclic voltammogram of $0.1 \mathrm{mM}$ TPA at a) Bare glassy carbon electrode; b) glassy carbon electrode $+T P A$; scan rate $50 \mathrm{mVs}^{-1}$; phosphate buffer of pH 7.0 as supporting electrolyte.

\subsection{Effect of $\mathrm{pH}$}

Figure 4 displayed effect of different $\mathrm{pH}$ on the response of $0.1 \mathrm{mM}$ TPA at GCE. When the $\mathrm{pH}$ changed from 4.2 to 10.4 , the anodic peak potential moved to negative direction indicates electro oxidation of TPA is $\mathrm{pH}$ dependence. With increasing $\mathrm{pH}$, the peak current increased until at about $\mathrm{pH}$ 7.0, and then decreased (Figure 5). The sharp and well defined oxidation peak was observed in phosphate buffer of $\mathrm{pH}$ 7. Hence, we have selected phosphate buffer of $\mathrm{pH} \mathrm{7,a}$ biological $\mathrm{pH}$ value, for further studies.

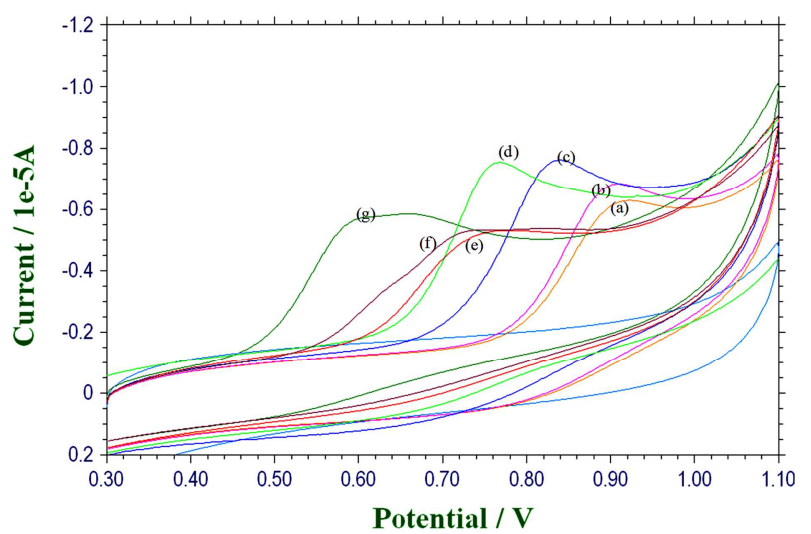

Figure 4. Influence of $p H$ on the shape of the anodic peak of TPA, (a) 4.2; (b) 5.0, (c)-6.0, (d) 7.0, (e) 8.0, (f) 9.2, (g) 10.4.

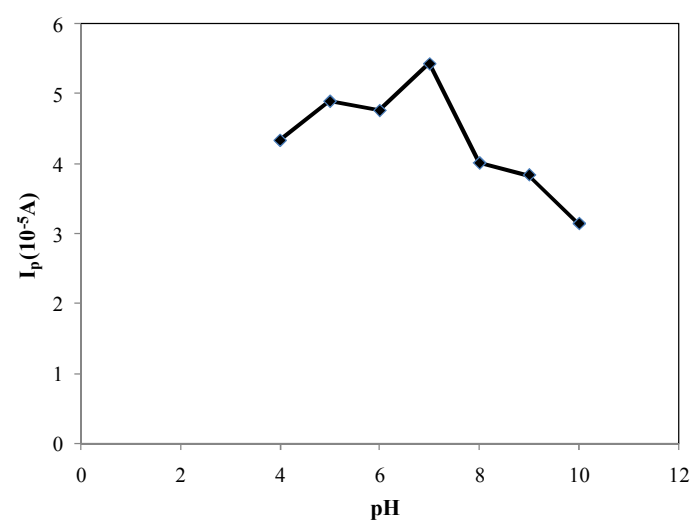

Figure 5. Variations of peak currents $I_{p a}(\mu A)$ of TPA with $p H$.

\subsection{Effect of Scan Rate}

The whole procedure for cyclic voltammetry was repeated for $0.1 \mathrm{mM}$ TPA with different scan rate value from 25 to $300 \mathrm{mVs}$ ${ }^{1}$ while other parameters were kept constant (Figure 6). In this scan rate range, the oxidation peak currents increased gradually along with increase in scan rate. There was a good linear relationship between anodic peak current and square root of scan rate $\left(v^{1 / 2}\right)$ as shown in Figure 7. The regression equation was $\mathrm{I}_{\mathrm{pa}}=$ $=5.158 v^{1 / 2}(\mathrm{~V} / \mathrm{s})+2.338\left(\mathrm{R}^{2}=0.987\right)$, which indicated that electron-transfer reaction of TPA on the GCE was diffusion controlled process. This was also supported by the slope of the plot $\log \mathrm{I}_{\mathrm{pa}}$ versus $\log$ scan rate was 0.102 .

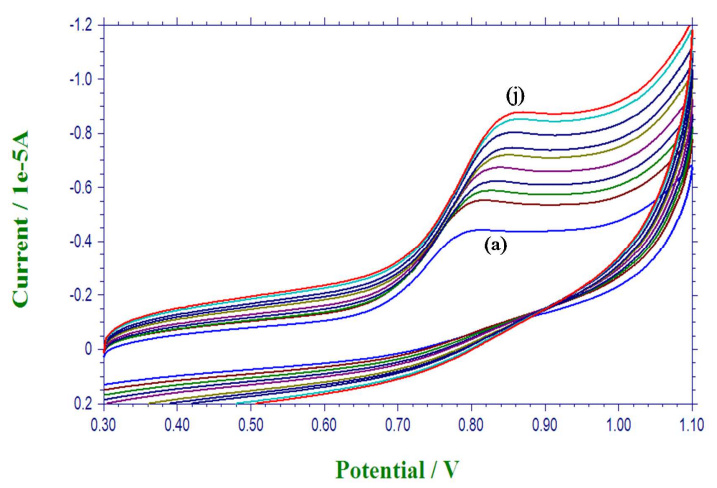

Figure 6. Cyclic voltammograms for the oxidation of TPA at different scan rates (a) - (j): $25 \mathrm{mV} / \mathrm{s}-300 \mathrm{mV} / \mathrm{s}$.

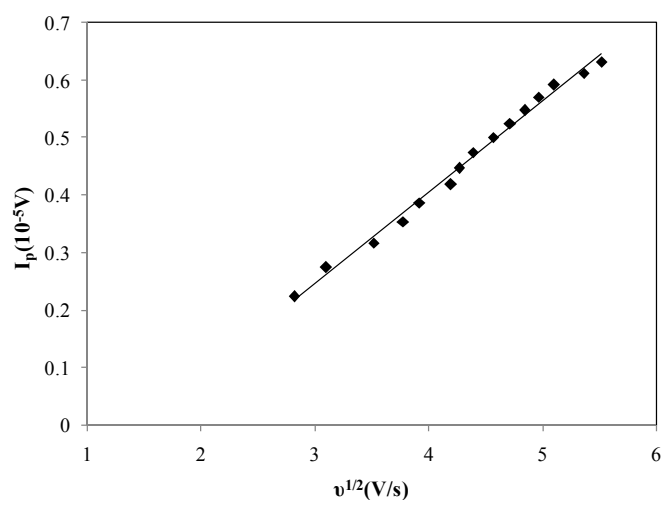

Figure 7. Dependence of oxidation peak current on the square root of scan rate. 


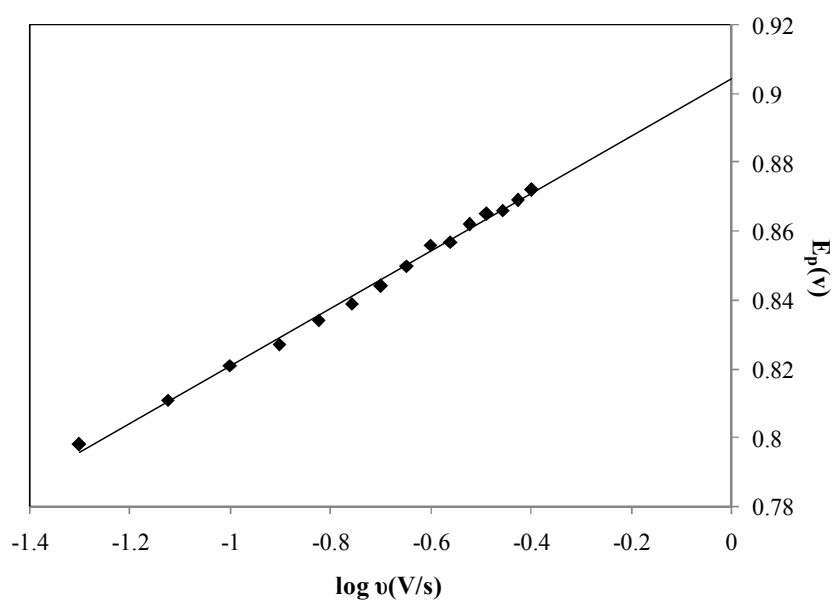

Figure 8. Dependence of oxidation peak potential on the logarithm of scan rate.

Moreover, TPA oxidation peak was shifted to more positive potentials with the increase in scan rate, an expected behavior of irreversible electrochemical reactions. A linear relationship was observed between $\mathrm{E}_{\mathrm{pa}}$ and $\log v$ in the range from 25 to $300 \mathrm{mV} \mathrm{s}^{-1}$ represented by a linear equation $\mathrm{E}_{\mathrm{pa}}=$ $0.056+0.896 \log v\left(\mathrm{R}^{2}=0.973\right)$, as shown in Figure 8:

The potential is defined by equation (2), according to the Laviron theory for irreversible systems [21]:

$$
\mathrm{E}_{\mathrm{pa}}=\mathrm{E}^{0^{\prime}}+\left(\frac{2.303 \mathrm{RT}}{\alpha \mathrm{nF}}\right) \log \left(\frac{\mathrm{RTk}^{0}}{\alpha \mathrm{nF}}\right)+\left(\frac{2.303 \mathrm{RT}}{\alpha \mathrm{nF}}\right) \log v
$$
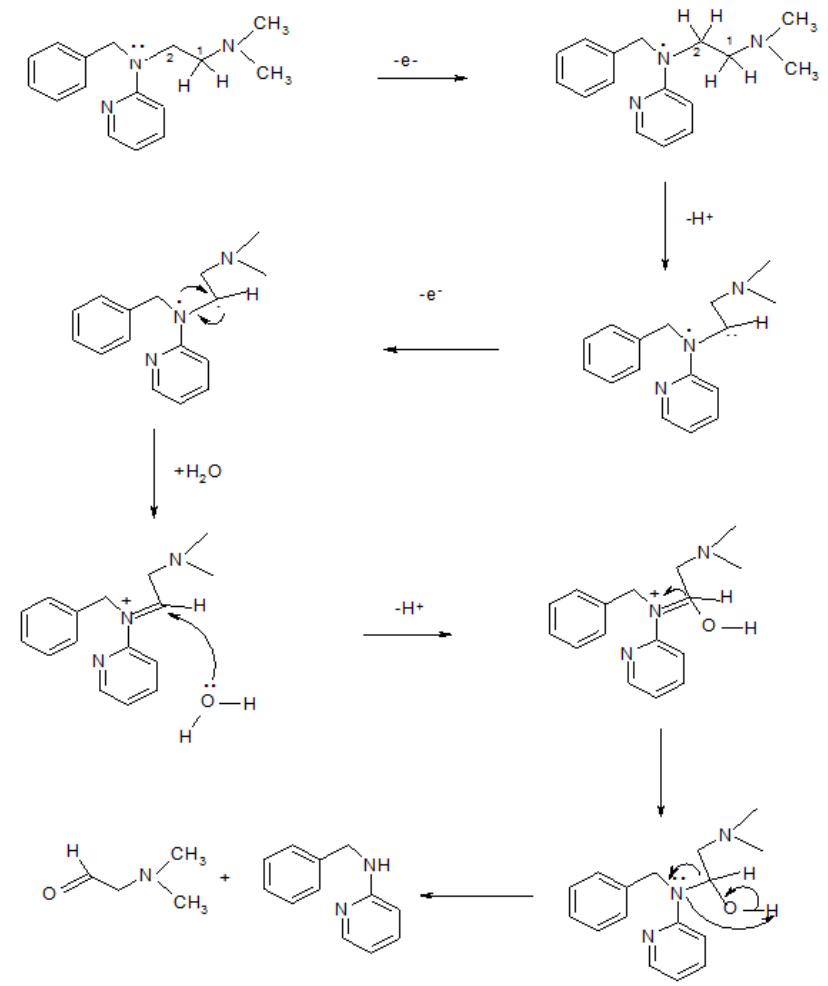

Figure 9. Probable electro-oxidation mechanism of TPA.

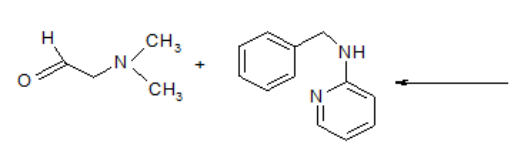

\subsection{Analytical Parameters}

Differential pulse voltammetry (DPV) was used for the where $\alpha$ is charge transfer coefficient, $\mathrm{k}^{0}$ is heterogeneous electron transfer rate constant, $\mathrm{n}$ is number of electrons transferred, $v$ is scan rate, and $\mathrm{E}^{0^{\prime}}$ is formal redox potential. Other symbols have their usual meanings. Thus, from the obtained slope of $\mathrm{E}_{\mathrm{pa}}$ versus $\log v$ and considering $\mathrm{T}=298 \mathrm{~K}$, $\mathrm{R}=8.314 \mathrm{~J} \mathrm{~K}^{-1} \mathrm{~mol}^{-1}$, and $\mathrm{F}=96485 \mathrm{C} \mathrm{mol}^{-1}$, the value of $\alpha \mathrm{n}$ can be easily calculated. Using the obtained slope of 0.056 and $\alpha=0.5$ for irreversible diffusion controlled process; number of transferred electrons was calculated to be $2.11 \approx$ 2.0 in the oxidation reaction. The an value was used for the determination of heterogeneous electron transfer rate constant. The value of $\mathrm{E}^{0^{\prime}}$ in equation (2) can be obtained from the intercept of $\mathrm{E}_{\mathrm{pa}}$ versus $v$ curve by extrapolating to the vertical axis at $v=0$ [22]. The intercept obtained for $\mathrm{E}_{\mathrm{pa}}$ versus $v$ plot was 0.811 . Thus, using this information and equation (2), the $\mathrm{k}^{0}$ value obtained was $1.332 \times 10^{3} \mathrm{~s}^{-1}$.

\subsection{Mechanism}

The number of electrons calculated was two, indicating that electro-oxidation of TPA on GCE involves transfer of two electrons and two protons per molecule of analyte. Figure 9 shows the probable electro oxidation mechanism for TPA by taking into account the number of electrons and protons transferred by calculation. There are two tertiary amines present in the molecule. The electro oxidation takes place at tertiary amine attached to pyridine ring [23].

quantification of TPA since DPV has a much higher current sensitivity and better resolution than cyclic voltammetry. It 
was used to estimate lower detection limit from voltammograms in which peaks are sharper and betterdefined than those obtained by cyclic voltammetry. The electrode showed linear behavior in the concentration range as represented in Figure 10. Figure 11 represents calibration plot of TPA at GCE electrode. The calibration plot was fitted with the equation of $\mathrm{I}_{\mathrm{pa}}(\mathrm{A})=530.08$ [TPA] +1.8503 $\left(\mathrm{R}^{2}=0.995\right)$. The detection limit was calculated to be $9.7 \times 10^{-}$ ${ }^{7} \mathrm{M}$, using the formula $(3 \mathrm{~s} / \mathrm{m})$, here $\mathrm{s}$ is standard deviation of peak currents of the blank (three runs) and $\mathrm{m}$ is the slope of calibration curve. Characteristics of calibration plot are as shown in Table 1. On comparing the detection limit and concentration ranges obtained by means of reported HPLC method [24], i.e. $0.7 \mu \mathrm{g} / \mathrm{mL}$ (LOD), 2-200 $\mu \mathrm{g} / \mathrm{mL}$ (Linearity range), we achieved lower detection limit and concentration range.

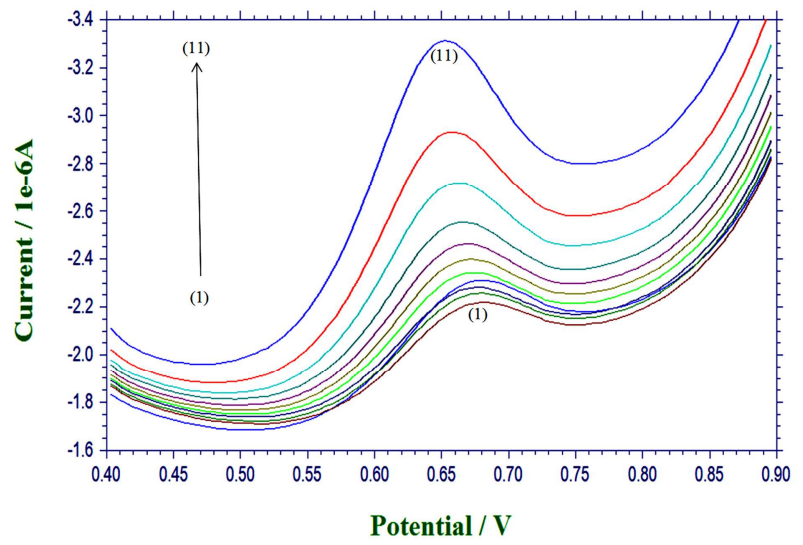

Figure 10. Differential pulse voltammograms for increasing concentration of TPA at GCE: (1) - (11): $0.9 \times 10^{-7} \mathrm{M}$ to $10 \times 10^{-5} \mathrm{M}$.

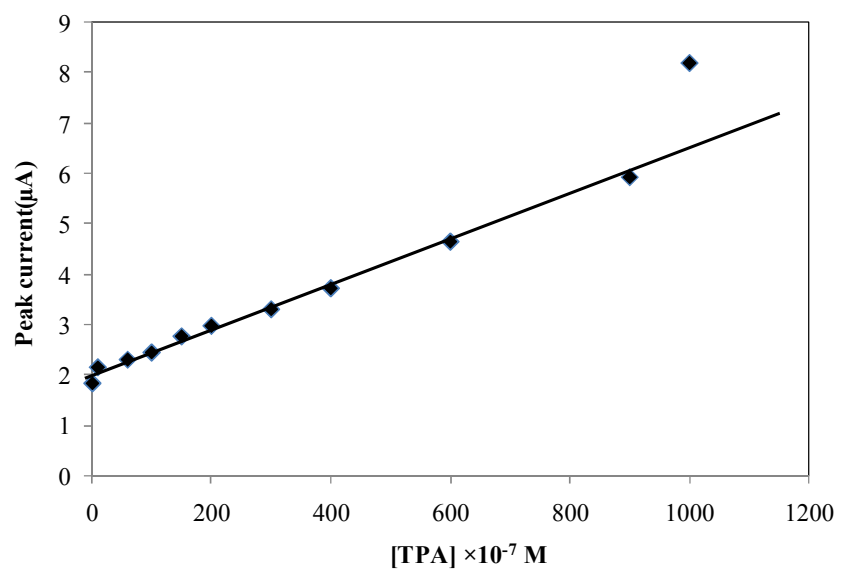

Figure 11. Plot of current against the concentration of TPA.

\subsection{Interference Study}

Under the optimized conditions, influence of various common interferences in pharmaceutical samples for the determination of TPA was studied. 100-fold Glucose, Gum Acacia, Sucrose, Citric acid, Dextrose, Lactose, Tartaric acid, Starch had no obvious interference with the current response of TPA (signal change below 10\%).
Table 1. Characteristics of TPA calibration plot using differential pulse voltammetry at glassy carbon electrode.

\begin{tabular}{ll}
\hline Linearity range $(\mathrm{M})$ & $0.9 \times 10^{-7}-10 \times 10^{-5}$ \\
Slope of the calibration plot & 530.08 \\
Intercept & 1.8503 \\
Correlation coefficient (r) & 0.995 \\
RSD of slope (\%) & 0.3239 \\
RSD of intercept (\%) & 0.3230 \\
Number of data points & 11.00 \\
LOD (M) & $9.7 \times 10^{-7}$ \\
LOQ (M) & $3.24 \times 10^{-6}$ \\
\hline
\end{tabular}

\subsection{Sample Analysis}

\subsubsection{Pharmaceutical Sample Analysis}

The proposed method was applied to determine TPA in Azaron tablets using DPV. Tablet sample was prepared as explained in the procedure section. The proposed method shows that recovery of TPA from Azaron tablet were in good agreement with labeled values of the tablet. A standard addition method was adopted to estimate accuracy of the proposed method. The measurement results are shown in Table 2. The recoveries of TPA standards added arein the range of $95.32 \%$ to $100.12 \%$.

Table 2. Results of the assay and the recovery test of TPA in pharmaceutical preparations using $D P V$.

\begin{tabular}{lll}
\hline & & Azaron tablet \\
\hline Labeled claim $(\mathrm{mg})$ & & 20.00 \\
${\text { Amount found }(\mathrm{mg})^{\text {a }}}$ & & 19.06 \\
Recovery $(\%)$ & & 95.31 \\
RSD $(\%)$ & & 00.42 \\
Amount of pure drug added $\left(10^{5} \mathrm{M}\right)$ & Found $\left(10^{5} \mathrm{M}\right)^{\text {a }}$ & Recovery \\
3 & 3.045 & 101.50 \\
5 & 5.006 & 100.12 \\
8 & 7.8422 & 98.02 \\
10 & 9.532 & 95.32 \\
\hline
\end{tabular}

${ }^{a}$ Average of three determinations

\subsubsection{Real Sample Analysis}

Voltammetric methods can be applied in real sample analysis in different areas such as biomedical, food, agriculture, and fishing industries. The developed differential pulse voltammetric method was applied for the determination and recovery of TPA from urine samples. The recoveries from urine were measured by spiking drug free urine with known amounts of TPA. The urine samples were diluted 100 times with the phosphate buffer solution before analysis without further pre-treatments. A quantitative analysis can be carried out by adding the standard solution of TPA $\left(1.0 \times 10^{-5}\right.$ $\mathrm{M})$ into the detect system of urine samples. The calibration graph was used for the determination of spiked TPA in urine samples. The detection results of four urine samples obtained are listed in Table 3. The recoveries determined were in the range from $97.07 \%$ to $100.50 \%$ with a good R.S.D. Thus satisfactory recoveries of analyte from real samples make the developed method applicable in clinical analysis. 
Table 3. Application of DPV to the determination of TPA in spiked human urine sample.

\begin{tabular}{|c|c|c|c|c|}
\hline Sample & $\operatorname{Added}\left(\times 10^{5} \mathrm{M}\right)$ & Found $^{a}\left(\times 10^{5} \mathrm{M}\right)$ & Recovery(\%) & R.S.D (\%) \\
\hline 1 & 2 & 1.9786 & 98.93 & 0.47 \\
\hline 2 & 5 & 4.8538 & 97.07 & 0.73 \\
\hline 3 & 6 & 6.0304 & 100.50 & 0.32 \\
\hline 4 & 8 & 7.8854 & 98.56 & 0.22 \\
\hline
\end{tabular}

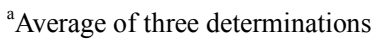

\section{Conclusion}

Tripelennamine hydrochloride exhibited an anodic peak at glassy carbon electrode. Based on this, a simple and sensitive electrochemical method was developed for the determination of TPA. This method had much strength including low cost, simple preparation process, good stability, excellent repeatability, and satisfactory sensitivity. The electrodic reaction process is an irreversible diffusion controlled, the number of electrons and protons transferred was calculated to be two. Based on the results suitable electrochemical mechanism was proposed. TheLower LOD of $9.7 \times 10^{-7} \mathrm{M}$ was obtained compared to reported methods. Better properties of the technique were also observed in comparison with few other analytical techniques which have already been developed for determination of TPA. Further, this method was applied for the recovery study of TPA in human urine samples.

\section{References}

[1] N. Elgrishi, K. J. Rountree, B. D. McCarthy, E. S. Rountree, T. T. Eisenhart and J. L. Dempsey, Journal ofChemical Education, 95 (2018) 196-206.

[2] A. J. Bard and L. R. Faulkner, Electrochemical Methods: Fundamentals and Applications, 2nd ed. (2001), New York: Wiley.

[3] W. Kemula and Z. Kublik, Nature, 182 (1958) 793-794.

[4] R. N. Adams, Electrochemistry at Solid Electrodes, (1968), Marcel Dekker, Inc., New York.

[5] P. T. Kissinger and W. R. Heineman, Cyclic voltammetry, Journal of Chemical Education, 60 (1983) 702-706.

[6] M. Noel and K. I. Vasu, Cyclic Voltammetry and the Frontiers of Electrochemistry, 1st Ed., (1990), Oxford and IBH Publishing Co. Pvt. Ltd., New Delhi.

[7] B. Uslu, S. A. Ozkan and Z. Senturk, Analytical ChimicaActa, 555 (2006) 341-347.

[8] J. Wang, Analytical Electrochemistry, 3rd ed. (2006), John Wiley and Sons, Inc., Hoboken, New Jersey.
[9] C. Amatore, E. Maisonhaute and G. Siminneau, Journal of Electroanalytical Chemistry, 486 (2000) 141-155.

[10] S. F. Cook, A. D. King, J. N. van den Anker and D. G. Wilkins, Journal of Chromatography B, 30 (2015) 30-42.

[11] A. Raza and T. M. Ansari, Analytical Chemistry Research, 4 (2015) 33-38.

[12] R. Nakao, M. Schou, C. Halldin, Journal of Chromatography A, 1266 (2012) 76-83.

[13] P. T. Kissinger, W. R. Heineman, Laboratory Techniques in Electroanalytical Chemistry, 2nd ed. (1996) Dekker, New York.

[14] L. R. Goldfrank and N. Flomenbaum, Goldfrank'sToxicologic Emergencies, (2006), McGraw-Hill Professional, p. 787.

[15] R. Oishi, S. Shishido, M. Yamori and K. Saeki, NaunynSchmiedeberg's Archives of Pharmacology, 349 (1994) 140144.

[16] T. Sato, K. Suemaru, K. Matsunaga, S. Hamaoka, Y. Gomita, R. Oishi, Japanese Journal of Pharmacology, 71 (1996) 81-84.

[17] S. Y. Yeh, C. Dersch, R. Rothman and J. L. Cadet, Synapse, 33 (1999) 207-217.

[18] B. W. McGwier, M. A. Alpert, H. Panayiotou and C. R. Lambert, Chest, 101 (1992) 1730-1732.

[19] B. Rezaei and Z. M. Zare, Analytical Letters, 41 (2008) 22672286.

[20] Y. Wang and Z. Z. Chen, Colloids and Surfaces B, 74 (2009) 322-327.

[21] E. Laviron, Journal of Electroanalytical Chemistry, 101 (1979) 19-28.

[22] W. Yunhua, J. Xiaobo and H. Shengshui, Bioelectrochemistry, 64 (2004) 91-97.

[23] J. I. Gowda and S. T. Nandibewoor, Electroanalysis, 28 (2016) 523-532.

[24] M. Podolska, A. Kulik, W. Bialecka, B. KwiatkowskaPuchniarz and A. Mazurek, Acta Poloniae Pharmaceutica Drug Research, 71 (2014) 709-719. 